\title{
REPRESENTAÇÕES SOCIAIS DOS ENFERMEIROS DE HOSPITAL GERAL DIANTE DO PACIENTE ALCOOLISTA*
}

Cely de Oliveira ${ }^{1}$, Divane de Vargas $^{2}$

RESUMO: Estudo de abordagem qualitativa objetivou analisar as representações sociais dos enfermeiros de hospital geral diante do paciente alcoolista. Os dados foram coletados em março de 2008 entre 20 enfermeiros de três hospitais gerais de uma cidade do interior de São Paulo, Brasil, por meio de registros autogravados e submetidos à Análise de Conteúdo norteada pelo referencial teórico-metodológico da representação social. Os resultados apontam que os enfermeiros concebem o paciente alcoolista como uma pessoa doente, portanto, o alcoolismo apresenta-se como uma doença sem, contudo considerar-se outros modelos explicativos para o uso do álcool, representação que se mostra atrelada mais ao senso comum do que ao conhecimento técnico-científico. Isso remete à necessidade de melhor preparo e capacitação dos profissionais em relação ao uso do álcool e alcoolismo, uma vez que a deficiência de conhecimento pode contribuir para a assistência fragmentada e pautada nas questões de ordem moral que permeiam o senso comum.

PALAVRAS-CHAVE: Enfermagem; Hospital; Alcoolismo.

\section{GENERAL HOSPITAL NURSES' SOCIAL REPRESENTATIONS OF ALCOHOLIC PATIENTS}

\begin{abstract}
This study, with a qualitative approach, aimed to analyze the social representations held by nurses in a general hospital, regarding the alcoholic patient. The data was collected in March 2008 from 20 nurses in three general hospitals in a city in the state of São Paulo, Brazil, through self-recorded records, and was submitted to Content Analysis guided by the theoretical-methodological framework of social representations. The results indicate that the nurses conceive the alcoholic patient as a sick person, therefore, alcoholism is shown as an illness without, however, considering other explanatory models for the use of alcohol - a representation which is linked more to folk knowledge than to technicalscientific knowledge. This points to the need for better preparation and training of the healthcare professionals in relation to the use of alcohol and alcoholism itself, as the shortage of knowledge may contribute to care which is fragmented and based on the moral considerations which permeate folk knowledge.
\end{abstract}

KEYWORDS: Nursing; Hospital; Alcoholism.

\section{REPRESENTACIONES SOCIALES DE LOS ENFERMEROS DE HOSPITAL GENERAL DELANTE DEL PACIENTE ALCOHOLISTA}

RESUMEN: Estudio de abordaje cualitativo cuyo objetivo fue analizar las representaciones sociales de los enfermeros de hospital general delante del paciente alcoholista. Los datos fueron obtenidos en marzo de 2008 entre 20 enfermeros de tres hospitales generales de una ciudad del interior de São Paulo, Brasil, por medio de registros autograbados y sometidos al Análisis de Contenido del referencial teórico-metodológico de la representación social. Los resultados indican que los enfermeros consideran el paciente alcoholista una persona enferma, por lo tanto, el alcoholismo se presenta como una enfermedad sin considerar otros modelos explicativos para el uso del alcohol; representación que se muestra relacionada más al sentido común que al conocimiento técnico-científico. Eso está asociado a la necesidad de más preparación y capacitación de los profesionales acerca del uso del alcohol y alcoholismo, ya que la falta de conocimiento puede contribuir para la asistencia fragmentada y basada en las cuestiones de orden moral que permean el sentido común.

PALABRAS CLAVES: Enfermería; Hospital; Alcoholismo.

* Este estudo foi extraído da dissertação de mestrado intitulada Representação dos enfermeiros de hospital geral frente ao paciente
alcoolista e a etiologia para o alcoolismo, apresentado ao Programa de Pós-Graduação em Enfermagem da Universidade de São Paulo, 2011.

${ }^{1}$ Enfermeira. Mestre em ciências. Professor da Universidade Paulista-UNIP deve constar assim: Enfermeira. Mestre em Ciências. Professora da Universidade Paulista. Membro colaborador do Grupo de Pesquisa em Álcool e Outras Drogas (GEAD) da Escola de Enfermagem da Universidade de São Paulo - EEUSP.

${ }^{2}$ Enfermeiro. Doutor em Enfermagem Psiquiátrica. Professor Associado do Departamento de Enfermagem Materno Infantil e Psiquiátrica Líder do Grupo de Estudos em àlcool e outras drogas EEUSP.

Autor correspondente:

Recebido: $11 / 10 / 2011$

Cely de Oliveira

Aprovado: 09/07/2012

Universidade de São Paulo

Av. Dr. Enéas de Carvalho Aguiar, 419 - 05403-000 - São Paulo-SP-Brasil

E-mail: celyolive@usp.br

Cogitare Enferm. 2012 Jul/Set; 17(3):452-7 


\section{INTRODUÇÃO}

Estima-se que cerca de $10 \%$ da população brasileira seja dependente do álcool, enquanto um número bem maior de pessoas enfrenta problemas decorrentes do consumo excessivo de bebidas alcoólicas, tais como acidentes de trânsito, situações de violência e perda de emprego. Na maioria das ocasiões sociais, o álcool encontra-se presente e torna-se quase onipresente em situações relacionadas à comemorações, momentos de descontração e relaxamento. É provável que isso ocorra por tratar-se de uma substância tão socialmente presente $^{(1)}$.

O álcool é uma das poucas drogas psicotrópicas que tem o consumo admitido e incentivado pela sociedade. Estudos realizados sobre o uso de drogas psicotrópicas no Brasil, em especial o álcool, apontam aumento significativo entre os anos de 2002 e 2005, atingindo principalmente a população jovem ${ }^{(2-3)}$. No ano de 2009 , o Ministério da Saúde (MS) divulgou uma pesquisa que indicou o aumento do consumo de bebidas alcoólicas entre os brasileiros. O consumo abusivo pela população foi de $19 \%$ em 2008, contra 17,5\%, em 2007 e 16,1\% em 2006, primeiro ano do levantamento ${ }^{(4)}$.

Os dados supracitados corroboram os do Departamento de Informática do SUS (Datasus) sobre as internações hospitalares no Brasil; no período entre 2001 e novembro de 2003 houve maior percentual de gastos hospitalares decorrentes do uso indevido de álcool. Os gastos relativos foram de $84,5 \%$ contra $14,5 \%$ relacionados a outras substâncias psicoativas ${ }^{(5)}$. Em 2004, de um total de 51.787 internações hospitalares em 367 hospitais psiquiátricos, o álcool foi o responsável por $39.186^{(6)}$.

Os dados epidemiológicos sobre os problemas relacionados ao álcool reforçam as indicações dos especialistas de que os profissionais da equipe de enfermagem prestam serviços nos mais diversos estabelecimentos de saúde e, independentemente do local onde atuem, estão sujeitos a ter contato com pessoas com problemas relacionados a essa substância. Podem, ainda, relacionar-se com filhos de alcoolistas ou prestar assistência a crianças e jovens expostos ao álcool. Neste sentido, os enfermeiros ficam em posição favorável para abordar os problemas decorrentes do seu consumo ${ }^{(7)}$. Geralmente, os enfermeiros consideram o alcoolismo uma doença, o que revela a influência do modelo moral de explicação do problema. A assistência de enfermagem centraliza-se nos sintomas da intoxicação aguda, em detrimento de ações que visem à identificação preco- ce e à prevenção do agravamento dos problemas ${ }^{(8-9)}$. Além disso, muitos se sentem incapacitados para a intervenção aos problemas provenientes do consumo do álcool ${ }^{(10)}$.

Em síntese, estudos revelam o aumento de pessoas com problemas decorrentes do uso de álcool e, também, o elevado número de internações tendo esse como causa, levando a supor que o enfermeiro terá maior contato com esses usuários dos serviços de saúde. Apesar dos estudos sobre atitudes e concepções diante do álcool e ao alcoolismo não serem escassos, seus resultados apontam, ainda, que as concepções dos enfermeiros são pautadas na moralidade. Julgou-se oportuno realizar um estudo para identificar e analisar as representações sociais de enfermeiros de hospital geral diante do paciente alcoolista.

\section{MÉTODO}

Trata-se de um estudo de abordagem qualitativa, as pesquisas dessa natureza caracterizam-se pela busca de compreensão das concepções e definições de determinada situação, tal como as pessoas a apresentam aos pesquisadores, possibilitando, assim, uma aproximação do universo de significações, motivos, aspirações e crenças dos enfermeiros estudados. A pesquisa qualitativa preocupa-se, ainda, com a realidade que não pode ser quantificada e a compreensão do mundo dos significados das ações e relações humanas ${ }^{(11)}$.

A coleta de dados foi realizada durante o mês de março de 2008 em três hospitais gerais de grande porte, privados, localizados no Município de Ribeirão Preto, São Paulo. Os estabelecimentos de assistência à saúde selecionados são de referência secundária e terciária, com elevada capacidade técnica e de atendimento especializado, que contam com importante número de enfermeiros e oferecem atendimento ininterrupto 24 horas. Participaram do estudo 20 enfermeiros, de ambos os sexos, de diferentes faixas etárias, selecionados intencionalmente, em cada turno. Os dados foram obtidos no próprio ambiente laboral, por meio de entrevistas semiestruturadas que continham três questões norteadoras relacionadas ao objetivo do estudo: Qual é sua opinião sobre as bebidas alcoólicas? O que você pensa sobre as pessoas que consomem bebidas alcoólicas? Como é o lidar no trabalho com pacientes alcoolistas?

Os dados foram submetidos a Análise de Conteúdo, tendo como suporte o referencial teórico-metodológico da representação social. Por meio da leitura repetida 
das entrevistas, procurou-se depreender os temas, os valores, as crenças e concepções dos sujeitos; as identificações das argumentações presentes no discurso e o reconhecimento da emergência das categorias empíricas $^{(11)}$. Da análise dos dados emergiram duas categorias empíricas denominadas: Representação social dos enfermeiros diante do paciente alcoolista e Representação da etiologia para o alcoolismo. Este estudo, no entanto, apresenta e analisa a primeira categoria mencionada.

A pesquisa foi aprovada pelo Comitê de Ética em Pesquisa da Escola de Enfermagem da Universidade de São Paulo, sob o Protocolo n. 709/2008.

\section{RESULTADOS}

A análise da categoria Representação social dos enfermeiros diante do paciente alcoolista originou três temáticas apresentadas a seguir:

\section{O alcoolista como uma pessoa doente}

A análise permitiu verificar que o alcoolista é concebido como uma pessoa doente e, como tal, deve ser tratado com medicações, como ilustram as falas que seguem:

É uma doença mesmo, vocêtem que ver a pessoa como doente. (E.9)

É um doente e tem que ser com medicações, né? (E.20)

\section{O alcoolista como uma pessoa com a qual é difícil lidar}

A análise sugere que os enfermeiros consideram uma situação complicada a abordagem aos pacientes alcoolistas quando estes dão entrada no serviço de hospital geral. Afirma-se que os profissionais de saúde não têm preparo para trabalhar com esse tipo de paciente, porque se apresenta agressivo e em situação de descontrole, como indica:

Tenho visto, principalmente agora trabalhando nesta parte de hospital geral, que a pessoa alcoolista é dificil, principalmente para os profissionais de saúde que não sabem lidar com essa questão, infelizmente. (E.4)

O lidar com paciente alcoolista representa, também, um desafio para os enfermeiros quando esses pacientes apresentam sinais e sintomas difíceis de identificar, como se observa nestas falas:

Tive essa experiência de paciente pegar um copo de leite e jogar em cima de mim. Tremor, agressividade, louco pra pegar no cigarro, pra sair, sabe? Já tive outras experiências com agressividade e prostração do alcoolismo, de paciente desmaiar, com hipoglicemia, necessitando demais do álcool [...]. Eu assustei, porque não estava preparada, então, eu assustei. (E.10)

Então, lógico que eu sei que é um problema, que, às vezes, ele é realmente um paciente mais difícil de lidar por que é um paciente que sai dos padrões de normalidade que nós estamos acostumados a ver. Ontem mesmo vieram dois pacientes etilistas aqui, um inclusive estava em delírio. (E.11)

A pouca experiência e a falta de preparo para trabalhar com o paciente alcoolista pode desencadear sentimentos de frustração no enfermeiro e, também, o descontrole emocional, como evidencia-se a seguir:

Então, se a gente não tem controle, se a gente não passa calma prá equipe, a gente [...] profissional acaba agredindo o paciente. Não é fácil trabalhar, não. (E.17)

Então, eu não tenho experiência, né? As únicas experiências que a gente tem são quando a gente pega o paciente em abstinência. Não é fácil, não, sabe? É difícil, tem que estar preparada, a gente tem que estar preparada prá isso e muitos de nós não estamos. A gente reconhece que a gente não está preparada prá isso. (E.18)

\section{O preconceito da equipe e o estigma diante do alcoolista}

Essa temática aborda a representação dos enfermeiros sobre o preconceito que esses usuários sofrem dentro dos serviços de saúde. Nesse caso, quando informam as concepções, os profissionais concebem o alcoolista como um "bêbado" que não tem direito de ser atendido em suas necessidades:

Ele é somente o bêbado [...] o bêbado que encheu a cara, encheu o camelo [...] o bebum. (E.4)

Ele é rotulado, "ah! Ele é bêbado", "ah! Lá vem aquele bebum". (E.5) 
É bêbado [...]. Então, a gente não tem que cuidar. (E.6)

A abordagem do paciente pelos profissionais da equipe, percebida e relatada pelos enfermeiros, está atrelada ao preconceito, como se observa nas falas que seguem:

Já vai buscar o bêbado? Quem bebe não presta [...]. Não tem que atender direito. (E.5)

Principalmente [o preconceito] dos profissionais que rotulam o paciente e já tinham esse estigma do paciente alcoolizado. Porque elas já carregavam esse preconceito. (E.8)

Todo mundo fala que bêbado, às vezes, enche o saco. (E.13)

\section{DISCUSSÃO}

A análise da representação dos enfermeiros diante do paciente alcoolista deste estudo possibilitou verificar que este é considerado um doente que deve ser tratado como tal. Porém, constata-se, ainda, que os enfermeiros concebem o paciente alcoolista como uma pessoa difícil, por apresentar agressividade. Portanto, a maioria dos profissionais não se considera preparada para trabalhar com esse tipo de paciente, sendo o atendimento dispensado permeado por preconceito e estigma.

Esses resultados podem estar relacionados à deficiência de conhecimento sobre as questões relacionadas ao alcoolismo por parte dos profissionais, sem considerar outros modelos explicativos para o uso do álcool. Os valores de ordem moral que ainda permeiam as representações da sociedade sobre o dependente de álcool e, portanto, as representações dos trabalhadores da saúde. O resultado deste estudo, quanto à concepção do alcoolismo como doença, corrobora estudo anterior ${ }^{(12)}$, que também constatou que o alcoolismo foi concebido pelos sujeitos de pesquisa como uma doença.

Pesquisa aponta que a concepção de que o alcoolismo é uma doença não é compartilhada somente por enfermeiros, mas, também, por docentes de Enfermagem; constatou-se que as concepções em relação ao fenômeno álcool e outras drogas encontram-se dentro do conceito de doença ${ }^{(13)}$.

Outros autores, ao realizarem estudo com estudantes de Enfermagem, apontam que as concepções destes diante do alcoolismo também são atreladas à doença.
Apesar do objeto central deste estudo ter sido a representação de enfermeiros, ressaltamos que a atuação do futuro profissional deve ser respaldada por conceitos adequados sobre a temática durante sua formação, uma vez que em seu cotidiano prestará assistência à clientela com problemas relacionados ao álcool ${ }^{(14)}$.

Em outro estudo, sobre a satisfação de trabalhar com pacientes alcoolistas, os autores observaram que a maioria dos enfermeiros preferia não trabalhar com esse tipo de paciente. Constataram, ainda, que os pacientes não tinham suas necessidades atendidas devido à alteração comportamental que chegava a produzir reações negativas: esses pacientes eram deixados de lado até que o efeito do álcool passasse ${ }^{(15)}$. A respeito desse resultado, os autores supuseram que as afirmações sobre o lidar com o paciente alcoolista podem mostrar-se carregadas de representações de cunho moral, pois os enfermeiros sentiram necessidade de afastar o alcoolista. Isso pode significar uma negação do fato como doença, uma tentativa de exclusão, por mau comportamento.

Tal dificuldade para lidar com paciente alcoolista pode ser explicada pela formação dos enfermeiros, que não recebem treinamento adequado sobre a temática. Como apontam autores de pesquisa sobre as atitudes dos enfermeiros diante do paciente alcoolista e do alcoolismo, há lacuna no conhecimento acerca das temáticas ${ }^{(16)}$.

$\mathrm{Na}$ representação dos enfermeiros deste estudo, o lidar com esse tipo de paciente está alicerçado no modelo moral de explicação para o uso do álcool, que, conforme pesquisa ${ }^{(17)}$ podem contribuir para que o paciente alcoolista seja representado como um paciente difícil. O fenômeno pode estar relacionado a outro resultado observado nesta pesquisa, de que o estigma e o preconceito permeiam a conduta e o atendimento oferecido pela equipe de saúde e, por consequência, dos profissionais de enfermagem diante dessa população.

Os resultados apresentados estão em concordância com pesquisa que constatou que as representações sociais dos enfermeiros de um serviço de emergência classificam o alcoolista como alguém que usurpa o atendimento de outros pacientes ${ }^{(18)}$. Outros autores corroboram esse resultado, pois apontam que tanto o enfermeiro como o futuro enfermeiro têm dificuldades na abordagem, no diálogo e no relacionamento interpessoal. Esses percebem o alcoolista como uma pessoa desagradável e, consequentemente, difícil, pois as crenças estereotipadas observadas entre os profissionais da saúde determinam o tipo e a qualidade dos 
cuidados dispensados, influenciando negativamente a comunicação entre enfermeiro e alcoolista ${ }^{(19)}$.

Assim, as representações dos enfermeiros indicam que o atendimento do alcoolista é influenciado pelo preconceito e pelo estigma, o que pode refletir questões advindas da era cristã, na qual o movimento "Temperança" marca a divisão entre uma posição mais liberal em relação ao álcool e outra, mais moralista, relacionada à Igreja Protestante. Em síntese, parte de uma visão da moralidade cristã em que alguém com dependência de substâncias psicoativas não tem fibra moral para resistir às tentações. No caso do alcoolismo, o indivíduo com problema seria aquele que não apresenta força de vontade, que é incapaz de resistir à tentação e acaba cedendo ao álcool ${ }^{(20)}$.

Esse fato é preocupante, pois os estudos comportamentais apontam que a visão dos trabalhadores não está centrada no alcoolismo como problema de saúde; que deve ser abordada sob vários modelos de atendimento. Mas, na crença da falta de capacidade de controle do consumo da substância, o que pode repercutir nas concepções dos profissionais.

Estudiosos afirmam que, para se trabalhar com alcoolistas, é importante autoconhecimento do enfermeiro, buscando identificar suas próprias crenças, valores e preconceitos em relação ao uso de drogas e aos usuários. Isso adquire relevância, pois os preconceitos podem ser pouco evidentes, passando despercebidos pelo profissional. Mas, esses se manifestam em seu comportamento, em abordagens inadequadas no momento do cuidado ou durante a orientação ao usuário de drogas ou seus acompanhantes.

Portanto, para prestar assistência a usuários de drogas, não bastam os conhecimentos de várias teorias e abordagens sobre a questão, também é necessário se conhecer. $\mathrm{O}$ estudo apresenta limitações pelo fato de ter envolvido sujeitos de um único município, que, embora atuem em instituições diferentes, provêm de uma mesma região geográfica. No entanto, apesar de não ser possível generalizar tais resultados, estes são relevantes por possibilitarem conhecer as representações sociais dos enfermeiros diante das questões relacionadas ao paciente alcoolista, contribuindo para o avanço do conhecimento sobre essa temática.

\section{CONSIDERAÇÕES FINAIS}

A prática da assistência, pesquisa e ensino em Enfermagem tem proporcionado o acúmulo de considerável experiência sobre o cuidado ao paciente com problemas relacionados ao uso do álcool. Essa experiência tem mostrado que há, entre os profissionais de enfermagem, grande necessidade de aquisição de conhecimentos teóricos que propiciem a revisão dos modelos ou protocolos informais que embasam a prática nessa área.

A representação social dos enfermeiros de hospital geral deste estudo expressa contradições e tensões, pois concebe o alcoolista como uma pessoa doente e, portanto, o alcoolismo se apresenta como uma doença. Apesar da concepção de doença, que as representações desses enfermeiros permitiram apreender, o que foi contemplado é que elas são calcadas em preconceito e estigma e/ou indicam que os enfermeiros não sabem como atender pacientes alcoolistas. Não se considera modelos que expliquem o uso de álcool e descrevam as características individuais da pessoa com problemas decorrentes do uso de álcool. Tampouco, os contextos no quais esta está inserida, tais como: social, cultural e econômico. Deve-se ter em vista que o conteúdo das falas dos enfermeiros é permeado por opiniões pautadas pelo senso comum.

As representações dos enfermeiros sobre a temática álcool e alcoolismo podem encontrar explicação na deficiência de conhecimento e, consequentemente, no despreparo no momento da abordagem ao paciente. Porém, faz-se necessária a busca constante de atualização sobre o tema. $\mathrm{O}$ atendimento aos indivíduos com complicações decorrentes do uso abusivo de álcool não é mais exclusividade de serviços especializados. Cabe ao profissional comprometer-se, também, com sua atualização para propiciar meios que facilitem sua prática de acordo com as necessidades da demanda por serviços de saúde.

\section{REFERÊNCIAS}

1. Laranjeira R, Pinsky I. Conhecer e enfrentar o alcoolismo. 5. ed. São Paulo: Contexto; 2005.

2. Carlini EA, Galduróz JCF, Noto AR, Nappo, SA. I Levantamento domiciliar sobre o uso de drogas psicotrópicas no Brasil: envolvendo as 107 maiores cidades do país. São Paulo: Cebrid/Unifesp; 2002.

3. Carlini EA, Galduroz JCF. II Levantamento domiciliar sobre o uso de drogas psicotrópicas no Brasil: em estudo envolvendo as 108 maiores cidades do país. São Paulo: Cebrid/Unifesp; 2006.

4. Brasil. Ministério da Saúde. Portal da Saúde. 2009 
[acesso em 15 out 2010]. Disponível: saude.gov.br/ portal/arquivos/pdf/vigitel

5. Brasil. Ministério da Saúde. A política do Ministério da Saúde para atenção integral a usuários de álcool e outras drogas. Série E. Legislação de saúde. Brasília (DF): Ministério da Saúde; 2004.

6. Vargas D. Atitudes de enfermeiros de hospital geral frente ao paciente alcoolista [dissertação]. Ribeirão Preto (SP): Universidade de São Paulo; 2001.

7. Vargas D, Labate RC, Costa Junior ML. Alcoolistas tratar ou punir: disposição de enfermeiros de hospital geral. Rev. enferm. UERJ. 2003;11(2):188-92.

8. Vargas D, Labate RC. Atitudes de enfermeiros de hospital geral frente ao uso do álcool e alcoolismo. Rev. bras. enferm. 2006;59(1):47-51.

9. Vargas D, Luis MAV. Álcool, alcoolismo e alcoolista: concepções e atitudes de enfermeiros de unidades básicas distritais de saúde. Rev. Latino-Am. Enfermagem. 2008; 16(n.esp.):543-50

10. Oliveira C, Vargas D, Soares J. Perception of nursing professionals of a general hospital dealing with alcohol and alcoholism. Rev. enferm. UFPE on line. 2011;(5):1352-6.

11. Minayo MCS. O desafio do conhecimento: pesquisa qualitativa em saúde. São Paulo: Hucitec; 2004.

12. Lucca DM, Vargas D. As concepções de enfermeiros de hospital geral frente às questões relacionadas ao álcool e ao alcoolismo. Rev. bras. enferm. 2006; 5(5):260-7.

13. Lopes GT, Pessanha HL. Concepções de professores de enfermagem sobre drogas. Esc. Anna Nery. 2008;12(3):465-72.

14. Carraro TE, Rassool GH, Luis MAV. A formação dos enfermeiros e o fenômeno das drogas no Sul do Brasil: atitudes e crenças dos estudantes de enfermagem sobre o cuidado. Rev. Latino-Am. Enfermagem. 2005;13(n. esp.):863-71

15. Vargas D, Labate RC. Trabalhar com alcoolistas: satisfação de enfermeiros de hospital geral. Rev. Gaúcha. Enferm. 2005;26(2):252-60.

16. Pillon SC. Atitudes dos enfermeiros com relação ao alcoolismo: uma avaliação de conhecimentos. Rev. Eletr. Enferm. 2005;7(3):301-5.
17. Vargas D. atitudes de enfermeiros frente as habilidades de identificação para ajudar o paciente alcoolista. Rev. bras. enferm. 2010;63(12):190-5

18. Assunção AN, Leopardi MT. Representações sociais de enfermeiros de emergência sobre o alcoolista. Cogitare enferm. 1996;1(1):15-23

19. Diniz AS, Ruffino MC. Influência das crenças do enfermeiro na comunicação com o alcoolista. Rev. Latino-Am. Enfermagem. 1996;4(n.esp.):17-23

20. Oliveira E. O desafio de assistir pacientes com transtornos decorrentes de uso prejudicial e/ou dependência de álcool e outras drogas [dissertação]. São Paulo(SP): Universidade de São Paulo; 2005. 